\title{
Metabolic Acid-Base Status In Critically III Patients: Is Standard Base Excess Correlated With Serum Lactate Level?*
}

\author{
O Metabolismo Ácido-Básico em Pacientes Críticos: É o Excesso de \\ Bases Padronizado Correlacionado com o Nível Sérico de Lactato?
}

\author{
Danilo Teixeira Noritomi ${ }^{1}$, Ricardo Reis Sanga ${ }^{1}$; André Carlos Kajdaksi-Balla Amaral ${ }^{1}$; Marcelo Park ${ }^{1}$
}

\section{RESUMO}

JUSTIFICATIVA E OBJETIVOS: Correlacionar o excesso de bases padronizado com o nível sérico de lactato e demonstrar a independência entre eles em relação a significância prognóstica.

MÉTODO: Em uma avaliação retrospectiva,nós recuperamos os dados de 333 pacientes de nosso banco de dados prospectivamente coletado em uma unidade de terapia intensiva clínica de 7 leitos de um hospital universitário terciário de 1800 leitos.

RESULTADOS: Nos resultados, achamos uma pobre correlação entre o excesso de bases padronizado e lactato, $r=-0,358, p<0,001$, e uma independente significância prognóstica de cada um quando analisados concomitantemente, odds ratio (Intervalo de confiança 95\%) =0,996 $(0,992-0,999)$ para o excesso de bases padronizado e 1,000 (1,000 - 1,002) para o lactato na admissão; e odds ratio (Intervalo de confiança $95 \%)=0,990(0,985-0,994)$ para o excesso de bases padronizado e 1,003 $(1,001-1,005)$ para o lactato após 24 horas da admissão. A acurácia do excesso de bases padronizado foi semelhante à do lactato em prever morte na internação na unidade de terapia intensiva.

1. Medical Intensive Care Unit - Hospital das Clínicas da Faculdade de Medicina da Universidade de São Paulo - São Paulo - Brazil

*Recebido da Unidade de Terapia Intensiva Clínica do Hospital das Clínicas da Faculdade de Medicina da Universidade de São Paulo, São Paulo, SP

Apresentado em 25 de novembro de 2005

Aceito para publicação em 02 de janeiro de 2006

Correspondence to:

Danilo Teixeira Noritomi, MD

Av Dom Pedro I, 198/42

06083-908, Osasco-SP Brazil

Phone: 55-11-36810666

Fax: 55-11-37721568

Email: dnoritomi@hotmail.com
CONCLUSÕES: O componente láctico do excesso de bases padronizado não é o maior determinante deste. O nível de lactato sérico e o excesso de bases padronizado são preditore independentes de mortalidade em pacientes críticos.

Unitermos: Acidose láctica; acidose metabólica; doença crítica; equilíbrio ácido básico; prognóstico.

\section{SUMMARY}

BACKGROUND AND OBJECTIVES: To correlate standard base excess (SBE) with serum lactate level and demonstrate the independent prognostic significance of each one.

METHODS: In a retrospective study, we retrieved data from 333 patients of our prospectively collected database of 7 -bed medical intensive care unit of a 1800-bed university hospital.

RESULTS: The results have shown a poor correlation between SBE and lactate, $r=-0.358, p<0.001$, and an independent prognostic significance of each one when analyzed concomitantly, odds ratio (95\% Confidence interval $)=0.996(0.992-0.999)$ to standard base excess and $1.000(1.000-1.002)$ to lactate at entrance; and odds ratio (95\% Confidence interval) $=0.990(0.985-0.994)$ to standard base excess and $1.003(1.001-1.005)$ to lactate after 24 hours. The accuracy of standard base excess was close to lactate to determine in-intensive care unit death.

CONCLUSIONS: The lactic component of the metabolic acidosis is not the major determinant of standard base excess. Serum lactate and SBE are independent outcome predictors in critically ill patients.

Key Words: Acid-base equilibrium; acidosis; critical illness; lactic acid, prognosis.

\section{INTRODUCTION}

Metabolic acidosis is common in critically ill patients 
and denotes great physiopathologic, clinical and prognostic features ${ }^{1,2}$. Traditionally, the acute metabolic acidosis in this context has been attributed to the presence of lactic acid, which is frequently seen in these patients ${ }^{3}$. However, recent studies in experimental and clinical field have stated that other several anions have an important role, sometimes even more important than lactate in the genesis and maintenance of this type of acid-base disturban$\mathrm{ce}^{4-6}$. Regarding the outcome prediction capacity of acid-base variables, some controversies still persist. Hyperlactatemia has been accepted for a long time as an important outcome prediction tool in several critical situations ${ }^{7,8}$. Nevertheless, it is not clear if its value persists independently of the degree of metabolic acidosis ${ }^{7,9}$.

The aim of this study was to correlate acute metabolic acidosis measured by base excess and hyperlactatemia in a medical intensive care unit population. For this purpose we have tested the mathematical correlation between standard base excess (SBE) and lactate, and also the independent prognostic significance of each one.

\section{METHODS}

We retrospectively retrieved our prospectively-collected data base from February 2000 to January 2001, and analyzed biochemical and clinical data collected on admission and after 24 hours from unselected consecutive patients admitted to a 7-bed medical intensive care unit of a tertiary level university hospital. Laboratorial information was routinely obtained from an arterial blood sample gained immediately after the insertion of an arterial catheter on admission to the intensive care unit, and after 24 hours. SBE and lactate were analysed in a blood gas analyser OMNI AVL (Roche Medical Instruments, Indianapolis, Indiana). The Van Slyke methodology is currently used to calculate SBE in this gas analyser ${ }^{10}$. No additional blood sampling was required. According to our ethic committee, informed consent was waived.

Data are shown as median and interquartile range. Spearman's test was used to study correlations between variables. Univariate analyses were used to correlate tested variables and intensive care unit mortality. Multivariate analysis was performed using a binary logistic regression model to test SBE and lactate concomitantly as an intensive care unit death predictor. The areas under the receiver operating characteristic (ROC) curves for the death prediction accuracy of SBE and lactate were calculated. It was used the commercially available statistical package SPSS 10.0 (SPSS Inc., Chicago, Illinois) to statistical analysis. The significance level considered was $\mathrm{p}<0.05$.

\section{RESULTS}

During 1-year period, 333 patients had complete data recorded available for retrieval. The general characteristics of patients are shown in table 1. The correlation between SBE and lactate is expressed individually on the admission and after 24 hours in graphic 1. For the prediction of intensive care unit death, we tested the following variables: age, APACHE II score, SBE and lactate (both on admission and after 24 hours). In the univariate analysis, besides the APACHE II score, SBE and lactate both on admission and after 24 were significantly associated with the intensive care unit mortality (Table 2). In the multivariate analysis, only SBE and lactate were concomitantly analyzed, and both still remained as independent death predictors when analyzed on admission, and when analyzed independently after 24 hours (Table 3). The ROC curves, on admission and after 24 hours, to SBE and lactate are shown in figure 2 .

Table 1 - General Characteristics of Patients

\begin{tabular}{l|c}
\hline \multicolumn{1}{c|}{ Characteristics } & Value \\
\hline Age (y/o) & $56(37,65)$ \\
APACHE II score * & $19(13,27)$ \\
Lactate at admission (mmol/L) & $2.4(1.4,10.0)$ \\
Lactate after 24 hours (mmol/L) & $2.2(1.3,8.0)$ \\
Base excess at admission (mmol/L) & $-6(-11,-2)$ \\
Base excess after 24 hours (mmol/L) & $-6(-11,-2)$ \\
Survivors - no \# (\%) & $177(53)$ \\
Renal failure - no \# (\%) & $67(20)$ \\
Diagnosis & no (\%) \\
Shock syndrome & $242(73)$ \\
$\quad$ Septic shock & $221(67)$ \\
$\quad$ Cardiogenic shock & $21(6)$ \\
Respiratory Failure & $47(14)$ \\
Sepsis & $36(10)$ \\
Post operative & $5(2)$ \\
Coma & $3(1)$ \\
\hline
\end{tabular}

${ }^{*}$ APACHE II score denotes Acute Physiological Chronic and Health Evaluation score and it ranges from 0 to 72 .

\# -no denotes the absolute number 


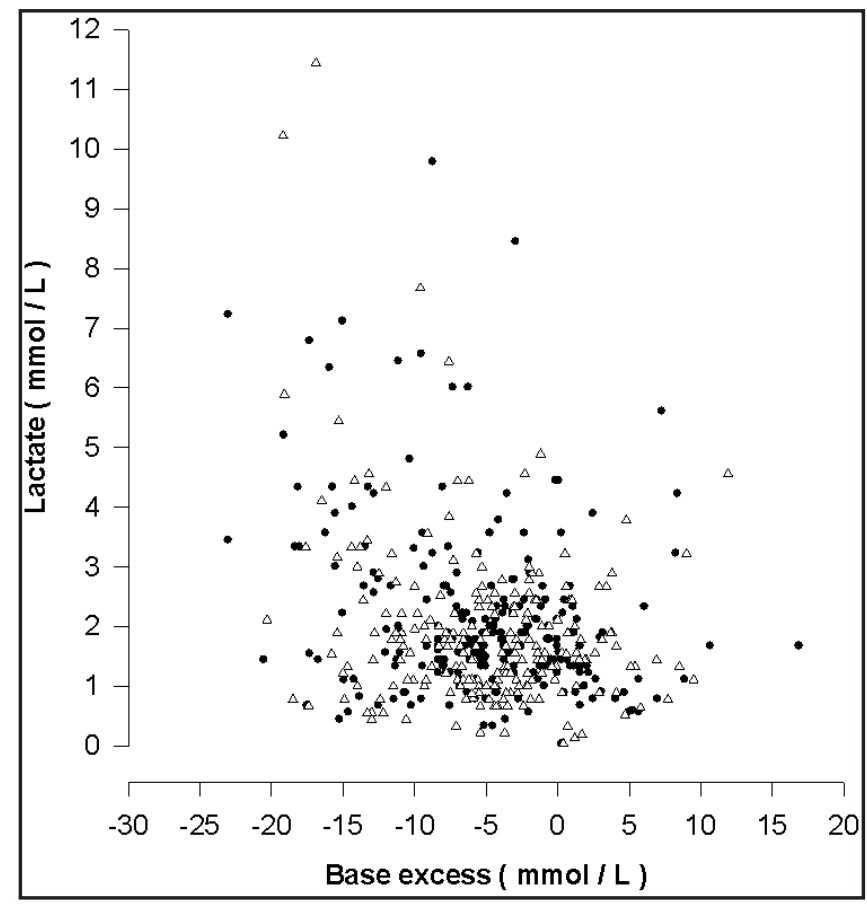

Figure 1 - Correlation Graphic between Base Excess and Lactate closed circles denote the entrance data $(r=-0.358, p<0.001)$ and open triangles denote the data after 24 hours $(r=-0.299, p$ $<0.001)$. $r$ is Spearman's coefficient.
Table 2 - Univariate Analysis of Death Predictor Characteristics

\begin{tabular}{l|c|c}
\hline \multicolumn{1}{c|}{ Data } & OR $-(\mathbf{C l ~ 9 5 \% )}$ & p-value \\
\hline Age & $1.013(0.998-1.029)$ & 0.099 \\
APACHE II & $1.114(1.081-1.148)$ & $<0.001$ \\
Base excess at entrance & $0.995(0.991-0.998)$ & 0.003 \\
Lactate at entrance & $1.001(1.000-1.002)$ & 0.009 \\
Base excess at 24 hours & $0.989(0.985-0.993)$ & $<0.001$ \\
Lactate at 24 hours & $1.003(1.001-1.005)$ & 0.010 \\
\hline
\end{tabular}

$\mathrm{OR}$ and $\mathrm{Cl}$ denote odds ratio and confidence interval respectively. The odds ratio associated with the listed factors are expressed as follows: age, the risk associated with each additional year; APACHE II score, the risk associated with each increment in the score as the risk of death; Base excess, the death risk associated with each $\mathrm{mmol} / \mathrm{L}$ increment in the base excess; Lactate, the death risk associated with each additional $\mathrm{mmol} / \mathrm{L}$ of lactate.

Table 3 - Multivariate Analysis of Lactate and Base Excess as a Death Predictor

\begin{tabular}{l|c|c}
\hline \multicolumn{1}{c|}{ Data } & OR (CI 95\%) & p-value \\
\hline \multicolumn{3}{c}{ At entrance } \\
\hline Base excess at entrance & $0.996(0.992-0.999)$ & 0.020 \\
Lactate At entrance & $1.001(1.000-1.002)$ & 0.029 \\
\hline \multicolumn{3}{c}{ After 24 hours } \\
\hline Base excess at 24 hours & $0.990(0.985-0.994)$ & $<0.001$ \\
Lactate at 24 hours & $1.001(1.001-1.005)$ & 0.004 \\
\hline
\end{tabular}

OR and $\mathrm{Cl}$ denote odds ratio and confidence interval respectively. The odds ratio associated with the listed factors are expressed as follows: Base excess, the death risk associated with each $\mathrm{mmol} / \mathrm{L}$ reduction in the base excess; Lactate, the death risk associated with each additional $\mathrm{mmol} / \mathrm{L}$ of lactate.

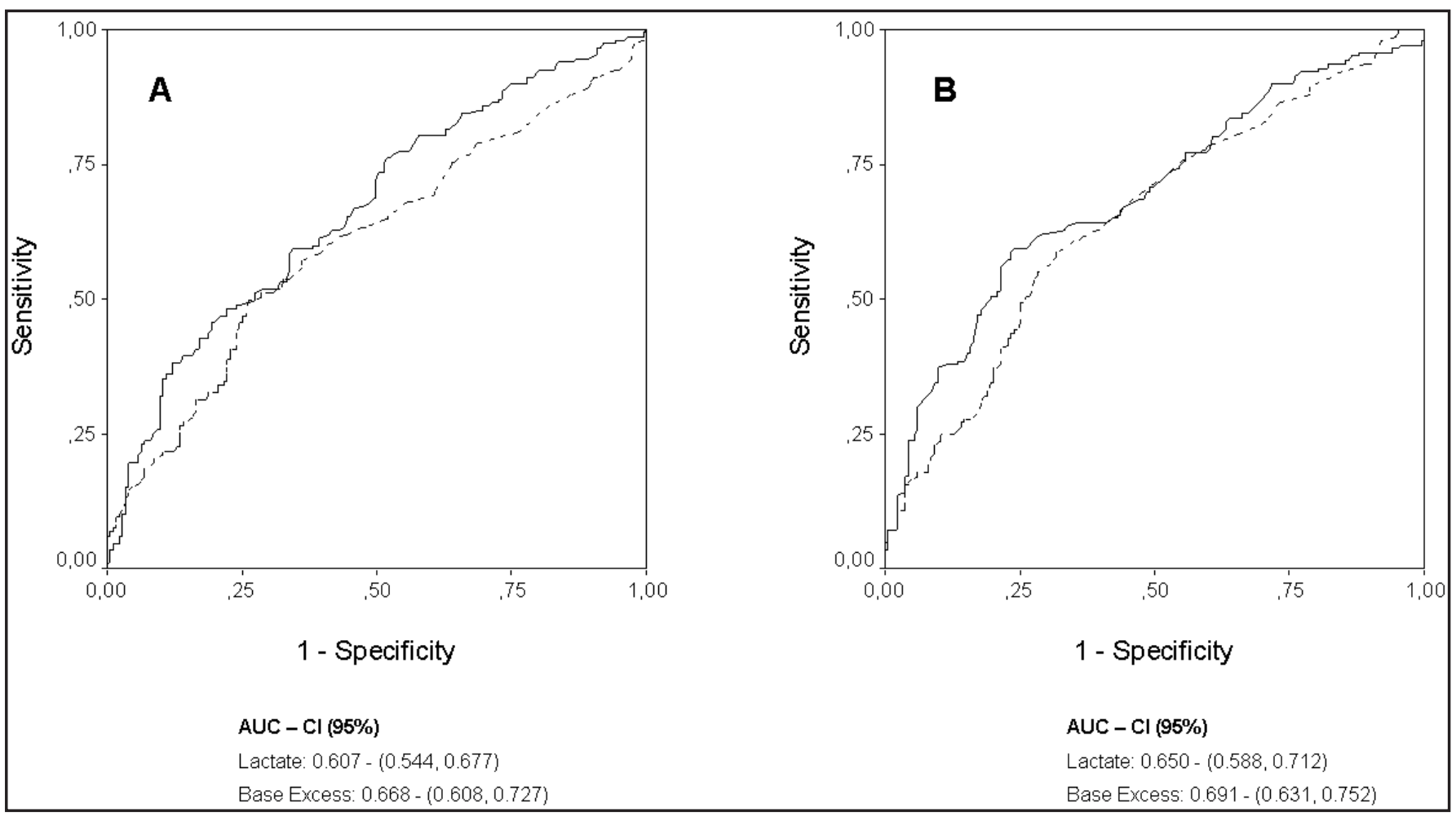

Figure 2 - Panel A shows the Receiver Operating Characteristic Curve of Base Excess and Lactate of Entrance at the Intensive Care Unit, and Panel B shows the Same after 24 hours. AUC Denotes Area under the Curve and CI Denotes Confidence Interval. 


\section{DISCUSSION}

Our results have shown a poor correlation between SBE and lactate, $r=-0.358, p<0.001$ (Figure 1), and an independent prognostic significance of each one when analyzed concomitantly, odds ratio (Confidence interval) $=0.996(0.992-0.999)$ to SBE and $1.001(1.000-1.002)$ to lactate on admission; and odds ratio (Confidence interval) $=0.990(0.985$ - 0.994) to SBE and $1.003(1.001-1.005)$ to lactate after 24 hours (Table 3 ). The accuracy to predict death of SBE was close to the lactate (Figure 2).

The existence of several potential mechanisms has been proposed to justify the complexity of acidbase disequilibrium frequently seen in critically ill patients. Hyperchloremia induced by volume expansion with routinely used solutions ${ }^{4,11}$ or differential shifts of chloride ion to and from the plasma ${ }^{4}$ seem to be an important cause of metabolic acidosis in several contexts. Renal failure and reduced acid clearance as a part of multiple organ dysfunction can result in decreased SBE by several reasons, increased levels of phosphate and unmeasureable anions probably are the most important ones ${ }^{12}$. Lactate and unmeasurable anions production by ischemic or inflamed tissues can represent another important cause of reduction in SBE in shock states $(1 ; 3)$. Hypoalbuminemia is an almost universal finding in ICU patients and its alkalinising effect has been shown to be quite significant according to the quantitative approach ${ }^{13}$. The relative weight of each disturbance in different clinical situations is far from being completely elucidated ${ }^{14}$.

The SBE offers an overview of acid basic metabolism independently of its complexity. The SBE does not disclose all metabolic acidosis ${ }^{15}$ but it is suggested that it may reflect the gastric mucosal intracellular $\mathrm{pH}{ }^{16}$. According to what was mentioned above, hyperlactatemia is only one possibility among several others to justify the SBE alteration seen in our population and the lack of association between the two variables is not completely unexpected. Applying the Stewart's acid-base methodology, it can be clearly demonstrated that lactate quantitative contribution to SBE alteration is quite small considering the range of values seen in clinical practice ${ }^{17,18}$.

From the mechanistic point-of-view, hyperlactatemia is also a partially explained finding. It is no longer considered a perfect marker of tissue hypoxia and several other conditions have been associated with $i^{3}{ }^{3}$. Nevertheless, lactate serum level is one of the most traditional laboratorial monitoring tools, and it is still used with success in diverse forms of critical diseases ${ }^{3,19}$.

In terms of outcome prediction capacity, some points are still under debate. SBE reflects a sum of several acid-base disturbances occurring concomitantly in each patient. Probably, each of these physiopathological processes carries different clinical meanings, for instance, it is suggested that predominantly hyperchloremic acidosis brings a better prognosis than lactic acidosis ${ }^{20}$. Despite this fact, can SBE still be used as an outcome prediction tool? Or should we focus our attention on more specific values, such as lactate or unmeasureable anions levels? Our results reaffirm that SBE still keeps a lactate-independent prognostic capacity. This goes in accordance with Smith et al. ${ }^{7}$ who have shown that prognostic information given by SBE is complementary to the lactate level prognostic prediction.

In a clinical scenario, Balasubramanyan et al. ${ }^{8}$ have shown that diminished SBE and base excess corrected to unmeasured anions are good death predictors in a pediatric intensive care unit. Smith et al. ${ }^{7}$ have found that the association of SBE and lactate levels can be especially useful in the outcome prediction. Hatherill et al. ${ }^{21}$ have shown in a paediatric critically ill population that the magnitude of metabolic acidosis measured by the SBE is not associated with mortality and that the lactate levels were more likely to predict outcome. Ultimately, Rocktaeschel et al. ${ }^{9}$ have shown that base excess is able to mark hyperlactatemia but not able to predict in-hospital death. This controversy has specially motivated our present study.

Limitations to our study include its retrospective nature and the lack of a complete quantitative analysis that could disclose the whole scenario of the acidbase disorder in our population, mainly characterizing the chloride and unmeasurable anions contributions.

In conclusion, the lactic component of the metabolic acidosis is not the major determinant of SBE. Serum lactate level and SBE are independent outcome predictors in critically ill patients.

\section{LIST OF ABBREVIATIONS USED}

SBE: standard base excess

ROC: receiver operating characteristic 


\section{REFERENCES}

01. Nimmo GR, Grant IS, Mackenzie SJ - Lactate and acid base changes in the critically ill. Postgrad Med J, 1991;67:(Suppl1):S56-S61.

02. Bellomo R - Bench-to-bedside review: lactate and the kidney. Crit Care, 2002;6:322-326.

03. De Backer D - Lactic acidosis. Intensive Care Med, 2003;29:699-702.

04. Kellum JA, Bellomo R, Kramer DJ et al - Etiology of metabolic acidosis during saline resuscitation in endotoxemia. Shock, 1998;9:364-368.

05. Kellum JA, Kramer DJ, Pinsky MR - Strong ion gap: a methodology for exploring unexplained anions. J Crit Care, 1995;10:51-55.

06. Dondorp AM, Chau TT, Phu NH et al - Unidentified acids of strong prognostic significance in severe malaria. Crit Care Med, 2004;32:16831688.

07. Smith I, Kumar P, Molloy S et al - Base excess and lactate as prognostic indicators for patients admitted to intensive care. Intensive Care Med, 2001;27:74-83.

08. Balasubramanyan N, Havens PL, Hoffman GM - Unmeasured anions identified by the Fencl-Stewart method predict mortality better than base excess, anion gap, and lactate in patients in the pediatric intensive care unit. Crit Care Med, 1999;27:1577-1581.

09. Rocktaeschel J, Morimatsu H, Uchino S et al - Unmeasured anions in critically ill patients: can they predict mortality? Crit Care Med, 2003;31:2131-2136

10. Morgan TJ, Clark C, Endre ZH - Accuracy of base excess--an in vitro evaluation of the Van Slyke equation. Crit Care Med, 2000;28:29322936.

11. Kellum JA - Fluid resuscitation and hyperchloremic acidosis in experimental sepsis: improved short-term survival and acid-base balance with
Hextend compared with saline. Crit Care Med, 2002;30:300-305.

12. Naka T, Bellomo R - Bench-to-bedside review: Treating acid-base abnormalities in the intensive care unit - the role of renal replacement therapy. Crit Care, 2004;8:108-114.

13. Figge J, Rossing TH, Fencl V - The role of serum proteins in acid-base equilibria. J Lab Clin Med, 1991;117:453-467.

14. Fencl V, Jabor A, Kazda A et al - Diagnosis of metabolic acid-base disturbances in critically ill patients. Am J Respir Crit Care Med, 2000;162:2246-2251.

15. Murray DM, Olhsson V, Fraser JI - Defining acidosis in postoperative cardiac patients using Stewart's method of strong ion difference. Pediatr Crit Care Med, 2004;5:240-245.

16. Boyd O, Mackay CJ, Lamb G et al - Comparison of clinical information gained from routine blood-gas analysis and from gastric tonometry for intramural pH. Lancet, 1993;16;341(8838):142-146.

17. Rackow EC, Mecher C, Astiz ME et al - Unmeasured anion during severe sepsis with metabolic acidosis. Circ Shock, 1990;30:107-115.

18. Mecher C, Rackow EC, Astiz ME et al - Unaccounted for anion in metabolic acidosis during severe sepsis in humans. Crit Care Med, 1991;19:705-711.

19. Bakker J, Coffernils M, Leon M et al - Blood lactate levels are superior to oxygen-derived variables in predicting outcome in human septic shock. Chest, 1991;99:956-962.

20. Brill SA, Stewart TR, Brundage SI et al - Base deficit does not predict mortality when secondary to hyperchloremic acidosis. Shock, 2002;17:459-462

21. Hatherill M, Waggie Z, Purves L et al - Mortality and the nature of metabolic acidosis in children with shock. Intensive Care Med, 2003;29:286-291. 